\title{
Erratum to: A Review of the Health Benefits of Greenness
}

\author{
Peter James $^{1,2}$ • Rachel F. Banay ${ }^{2}$ - Jaime E. Hart ${ }^{2,3}$ - Francine Laden ${ }^{1,2,3}$
}

Published online: 25 June 2015

(C) Springer International Publishing AG 2015

Erratum to: Curr Epidemiol Rep (2015) 2:131

DOI 10.1007/s40471-015-0043-7

The original version of this article did not signify the shared first authorship of Peter James and Rachel F. Banay for the work completed. Both authors contributed equally to this work.

The online version of the original article can be found at http://dx.doi.org/ 10.1007/s40471-015-0043-7.

$\triangle$ Rachel F. Banay

rachel.banay@mail.harvard.edu

1 Department of Epidemiology, Harvard T.H. Chan School of Public Health, 401 Park Dr, 3rd Floor West, Boston, MA 02215, USA

2 Department of Environmental Health, Harvard T.H. Chan School of Public Health, 401 Park Dr, 3rd Floor West, Boston, MA 02215, USA

3 Channing Division of Network Medicine, Department of Medicine, Brigham and Women's Hospital and Harvard Medical School, 401 Park Dr, 3rd Floor West, Boston, MA 02215, USA 